\title{
What Should Be Done to Increase Survival in Patients With Colorectal Cancer?
}

\author{
Min Ro Lee, Jong Hun Kim \\ Research Institute of Clinical Medicine, Chonbuk National University Medical School, Jeonju, Korea
}

\section{See Article on Page 144-150}

As a result of its rapid increase, colorectal cancer (CRC) in Korea was the third most common cancer in 2010. The age-standardized incidence rate of CRC was 20.4 (per 100,000) in 1999 and increased to 35.9 in 2010 (annual percentage changes, 5.9\%). In 2010, 25,782 new CRC cases (15,612 men and 9,918 women) were diagnosed [1]. The article used the Korea Central Cancer Registry (226,352 cases) to show that the 5-year relative survival rates had improved between 1993 and 2010 (55.4\% for 1993-1995 and $72.6 \%$ for 2006-2010) [2]. The rapid increase in CRC incidence is mainly attributed to the increase in colon cancer, especially distal colon cancer, and may be explained by a transition of risk factors for subsites or by the effect of CRC screening. The survival improvement may be due to an increase in early detection, refinement of surgical technique, new chemotherapy agents, and a multidisciplinary approach. CRC screening is a common denominator of the rapid increase in the incidence rate and the improved survival.

CRC screening programs were introduced in 2004 as a part of the National Cancer Screening Program for Medical Aid recipients and National Health Insurance beneficiaries in the lower income bracket. Fecal occult blood test (FOBT) is provided free of charge as a primary modality for men and women aged 50 years or older. FOBT-positive individuals are provided follow-up by either colonoscopy or double-contrast barium enema. The participation rate was only $10.5 \%$ in 2004 , but it increased to $21.1 \%$ in 2008 [3]. We colorectal surgeons still have a long way to go before we achieve our goal of complete healing of CRC. An expansion of

Correspondence to: Jong Hun Kim, M.D.

Research Institute of Clinical Medicine, Chonbuk National University Medical School, 567 Baekje-daero, Deokjin-gu, Jeonju 561-756, Korea

Tel: +82-63-250-1570, Fax: +82-63-271-6197

E-mail: Kimjhun@chonbuk.ac.kr

(c) 2013 The Korean Society of Coloproctology

This is an open-access article distributed under the terms of the Creative Commons Attribution NonCommercial License (http://creativecommons.org/licenses/by-nc/3.0) which permits unrestricted noncommercial use, distribution, and reproduction in any medium, provided the original work is properly cited. an adherent to CRC screening program and an extension to surveillance colonoscopy without FOBT are the crux of the matter.

\section{REFERENCES}

1. Jung KW, Won YJ, Kong HJ, Oh CM, Seo HG, Lee JS. Cancer statistics in Korea: incidence, mortality, survival and prevalence in 2010. Cancer Res Treat 2013;45:1-14.

2. Park HC, Shin A, Kim BW, Jung KW, Won YJ, Oh JH, et al. Data on the characteristics and the survival of Korean patients with colorectal cancer from the Korea Central Cancer Registry. Ann Coloproctol 2013;29:144-50.

3. Choi KS, Lee HY, Jun JK, Shin A, Park EC. Adherence to followup after a positive fecal occult blood test in an organized colorectal cancer screening program in Korea, 2004-2008. J Gastroenterol Hepatol 2012;27:1070-7. 